City University of New York (CUNY)

CUNY Academic Works

\title{
A Multi-temporal Analysis of AMSR-E Data for Flood and Discharge Monitoring during the 2008 Flood in lowa
}

\author{
Marouane Temimi \\ CUNY City College \\ Teodosio Lacava \\ National Research Council \\ Tarendra Lakhankar \\ CUNY City College \\ Valerio Tramutoli \\ University of Basilicata \\ Hosni Ghedira \\ Masdar Institute
}

See next page for additional authors

\section{How does access to this work benefit you? Let us know!}

More information about this work at: https://academicworks.cuny.edu/cc_pubs/220

Discover additional works at: https://academicworks.cuny.edu

This work is made publicly available by the City University of New York (CUNY).

Contact: AcademicWorks@cuny.edu 


\section{Authors}

Marouane Temimi, Teodosio Lacava, Tarendra Lakhankar, Valerio Tramutoli, Hosni Ghedira, Riadh Ata, and Reza Khanbilvardi 


\title{
A multi-temporal analysis of AMSR-E data for flood and discharge monitoring during the 2008 flood in Iowa
}

\author{
Marouane Temimi, ${ }^{1 *}$ Teodosio Lacava, ${ }^{2}$ Tarendra Lakhankar, ${ }^{1}$ Valerio Tramutoli, ${ }^{3}$ \\ Hosni Ghedira, ${ }^{4}$ Riadh Ata $^{5}$ and Reza Khanbilvardi ${ }^{1}$ \\ ${ }^{1}$ NOAA-CREST, City University of New York, 160 Convent Avenue, New York, NY, 10031, USA \\ ${ }^{2}$ Institute of Methodologies for Environmental Analysis (IMAA) -National Research Council (CNR), C.da Santa Loja, 85050, Tito Scalo (PZ), Italy \\ ${ }^{3}$ Department of Engineering and Physics of Environment (DIFA) -University of Basilicata - via dell'Ateneo Lucano, 10, 85100 Potenza, Italy \\ ${ }^{4}$ Water and Environmental Engineering Program, Masdar Institute, Abu Dhabi, United Arab Emirates \\ ${ }^{5}$ Electricité de France EDF LNHE/ National Hydraulics and Environment Lab., Chatou, France
}

\begin{abstract}
:
The objective of this work is to demonstrate the potential of using passive microwave data to monitor flood and discharge conditions and to infer watershed hydraulic and hydrologic parameters. The case study is the major flood in Iowa in summer 2008. A new Polarisation Ratio Variation Index (PRVI) was developed based on a multi-temporal analysis of $37 \mathrm{GHz}$ satellite imagery from the Advanced Microwave Scanning Radiometer (AMSR-E) to calculate and detect anomalies in soil moisture and/or inundated areas. The Robust Satellite Technique (RST) which is a change detection approach based on the analysis of historical satellite records was adopted. A rating curve has been developed to assess the relationship between PRVI values and discharge observations downstream. A time-lag term has been introduced and adjusted to account for the changing delay between PRVI and streamflow. Moreover, the Kalman filter has been used to update the rating curve parameters in near real time. The temporal variability of the $b$ exponent in the rating curve formula shows that it converges toward a constant value. A consistent 21-day time lag, very close to an estimate of the time of concentration, was obtained. The agreement between observed discharge downstream and estimated discharge with and without parameters adjustment was 65 and $95 \%$, respectively. This demonstrates the interesting role that passive microwave can play in monitoring flooding and wetness conditions and estimating key hydrologic parameters. Copyright (c) 2011 John Wiley \& Sons, Ltd.
\end{abstract}

KEY WORDS flood; river discharge; soil moisture; passive microwave; Kalman filter

Received 9 April 2010; Accepted 20 January 2011

\section{INTRODUCTION}

Major floods were observed in Upper Mississippi Watershed in June 2008. Much of central and eastern Iowa was affected by a 500-year flood which was classified as the worst in the history of the region (http://www. flood2008.iowa.gov/). Major damages and large inundated areas related to these floods have been recorded. Remote sensing data and particularly, passive microwave images, have been largely used to monitor these extreme events (Crow et al., 2005; Schmugge, 1998; Sippel et al., 1998). Three main reasons motivate the use of passive microwave data which are namely their high temporal resolution, their large spatial coverage and the capability of the signal to penetrate through clouds. Despite the great interest in low frequencies such as $\mathrm{L}$ and $\mathrm{C}$ bands which are more appropriate for soil moisture retrieval, other studies have explored the potential of the $37 \mathrm{GHz}$ channel to monitor flood conditions (Brakenridge et al., 2007; Sippel et al., 1994; Tanaka et al., 2000; Ferrazzoli et al. 2010).

\footnotetext{
* Correspondence to: Marouane Temimi, NOAA-CREST, City University of New York, 160 Convent Avenue, New York, NY, 10031, USA.

E-mail: mtemimi@ccny.cuny.edu
}

The 37-GHz Polarisation Difference $\left(\mathrm{PD}=\mathrm{Tb}_{\mathrm{v}}\right.$ $\mathrm{Tb}_{\mathrm{h}}$ ) where $\mathrm{Tb}$ is the brightness temperature and $\mathrm{v} / \mathrm{h}$ refers to vertical/horizontal polarisation has been used to monitor flooded areas (Choudhury, 1989; Sippel et al., 1994; Tanaka et al., 2003). Sippel et al. (1994) applied the index to delineate the extent of flooding along the Amazon River through the use of an established relationship between the river stage and flooded area extent (Sippel et al., 1998). A similar relationship was also successfully applied by Hamilton et al. (2004). Kerr and Njoku (1993) used, on the other hand, the Polarisation Ratio $\left(\mathrm{PR}=\left(\mathrm{Tb}_{\mathrm{v}}-\mathrm{Tb}_{\mathrm{h}}\right) /\left(\mathrm{Tb}_{\mathrm{v}}+\mathrm{Tb}_{h}\right)\right)$ because it is less affected by atmospheric conditions and insensitive to surface temperature (Njoku and Chan, 2006; Owe et al., 2001). The same index was used by Paloscia et al. (2001) to assess the vegetation effect and to retrieve soil moisture using observations from the Special Sensor Microwave Imager (SSM/I). In order to distinguish the soil moisture contribution from vegetation and soil roughness contributions to the measured signal, Lacava et al. (2005a) successfully applied the Robust Satellite Techniques (RST) approach (Tramutoli et al., 2005, 2007) to Advanced Microwave Sounding Unit (AMSU) data. More recently, Temimi et al. (2007) used PR with other ancillary data to account for vegetation heterogeneity and 
to estimate soil moisture in a large northern watershed. Also, Tanaka et al. (2003) have found a good agreement between derived water extent from brightness temperature observed at $37 \mathrm{GHz}$ and AVHRR images.

The use of microwave observations at high frequencies was also expanded to infer hydraulic variables. Brakenridge et al. (2007) used AMSR-E $37 \mathrm{GHz}$ brightness temperature to globally infer river discharge. The same AMSR-E frequency was also used by Temimi et al. (2005) to monitor streamflow in the Mackenzie River Basin in Canada. Their findings coincided with those by Smith et al. (1996) and Bjerklie et al. (2003) which demonstrated the feasibility of measuring river discharge from space. In another study, Smith and Pavelsky (2008) estimated the flood wave propagation speed using remote sensing data. Their analysis was based on a rating curve relationship which is largely used in river hydraulics to estimate river discharge or stage (Frazier et al., 2003; Smith et al., 1996). The river effective width has been used as proxy for the inundation extent (Ashmore and Sauks, 2006; Smith and Pavelsky, 2008). Smith and Pavelsky (2008) also demonstrated the possible transferability of this relationship between different sections along the river. In addition, Bjerklie et al. $(2003,2005)$ have inferred river discharge using remotely sensed hydraulic variables. Other studies demonstrated that assimilating satellite based discharge estimates into hydrological/hydraulic models lead to an improvement in their performance (Montanari et al., 2009; Neal et al., 2009).

This study investigates the use of passive microwave data for flood and river discharge monitoring. In particular, the relationship between the extent of inundated/wet areas and observed discharge downstream is analysed. Also, the potential of using passive microwave data to assess key hydrologic and hydraulic parameters is evaluated.

\section{METHODOLOGY}

\section{Study area}

The study area which was largely affected by the flood event in 2008 is located in Iowa and part of the Upper Mississippi watershed (Figure 1). It is drained by the Des Moines, Cedar, and Iowa Rivers which are tributaries of the Mississippi River. During the first week of June 2008, very intense precipitations have been recorded throughout the Midwest and particularly in Iowa. Most of these precipitations occurred over a short period of time and generated flash flood conditions. It is very important to add that these rainfalls were preceded by a particularly wet winter and spring seasons. These exceptional conditions were the second wettest since 1895 (NCDC, 2008). They fostered the drainage of almost the total amount of rainfall received in June.

The Turkey River, the Maquoketa River, the Upper Iowa River, the Iowa River (and its main tributaries), the Cedar River (and its main tributaries), and the Skunk
River all exceeded their overbank flooding stages. The flood burst at least 25 levees in Missouri, Iowa, and Illinois. Two of the largest cities in Iowa, Iowa City of Johnson County and Cedar Rapids of Linn County were significantly affected by the flooding (Hoke, 2009). Cedar River inundated a large portion of Cedar Rapids with 12 foot flood-stage causing substantial damages of a value around US \$737 million (Coleman and Budikova, 2010). The total cost of the damages associated to the flood event is around US $\$ 10$ billion. By mid-June, the Federal Emergency Management Agency (FEMA) had declared 85 out of the 99 Iowa counties disaster areas. An estimation of 1.2 million acres of corn and soybean crops was lost due to the flood (RIO, 2009).

Areas along the Iowa River and its major tributary, Cedar River, were the most affected by the 2008 flood event. Des Moines River, the second largest River in the state after Iowa River, was also subject to overbank flooding. Three main reservoirs exist along these rivers. The impact of these reservoirs on the drainage delay and its relationship with the discharge downstream in the Mississippi river is not considered in this study.

\section{Data}

The proposed methodology makes use of AMSR-E vertically and horizontally polarized brightness temperatures observed at $37 \mathrm{GHz}$ from June 2002 to August 2008. AMSR-E observations are taken at least twice a day from ascending and descending overpasses. AMSR-E level 2A product has been used in this study. All AMSRE data were obtained from National Snow and Ice Data Center (http://nsidc.org).

The Field of View (FOV) of AMSR-E is larger at lower frequencies as it varies from $43 \times 75 \mathrm{~km}$ at the $6.9 \mathrm{GHz}$ to $8 \times 14 \mathrm{~km}$ at the $37 \mathrm{GHz}$ channel. The $37 \mathrm{GHz}$ channel compromises between spatial resolution and atmospheric perturbations. AMSR-E observations at lower frequencies (i.e. 6.7, 10.7, and $19 \mathrm{GHz}$ ), despite their sensitivity to soil moisture, are relatively coarse in term of spatial resolution. The $89 \mathrm{GHz}$ channel has the finest spatial resolution $(5 \mathrm{~km})$. However, it is substantially affected by atmospheric perturbations mainly because of the $\mathrm{O}_{2}$ contamination (Brakenridge et al., 2007). Recently, Ferrazzoli et al. (2010) have monitored rainstorm and flooding events through the estimation of the polarisation ratio at three AMSR-E frequencies namely, the $6 \cdot 9,10 \cdot 7$, and $37 \mathrm{GHz}$ which correspond to the C, X, and Ka bands respectively. They noticed better capabilities in delineating the waterbodies and inundated areas at the Ka band because of the higher spatial resolution. In term of temporal variation the polarisation ratios at the three frequencies have shown very similar behaviour with a mitigated temporal variability at the $\mathrm{C}$ band.

In this study, we are expanding our analysis to the time periods before and after the flood event to better comprehend the drainage delays with respect to the magnitude of the flood event and study the link with discharge observed downstream. Rivers discharge observed 


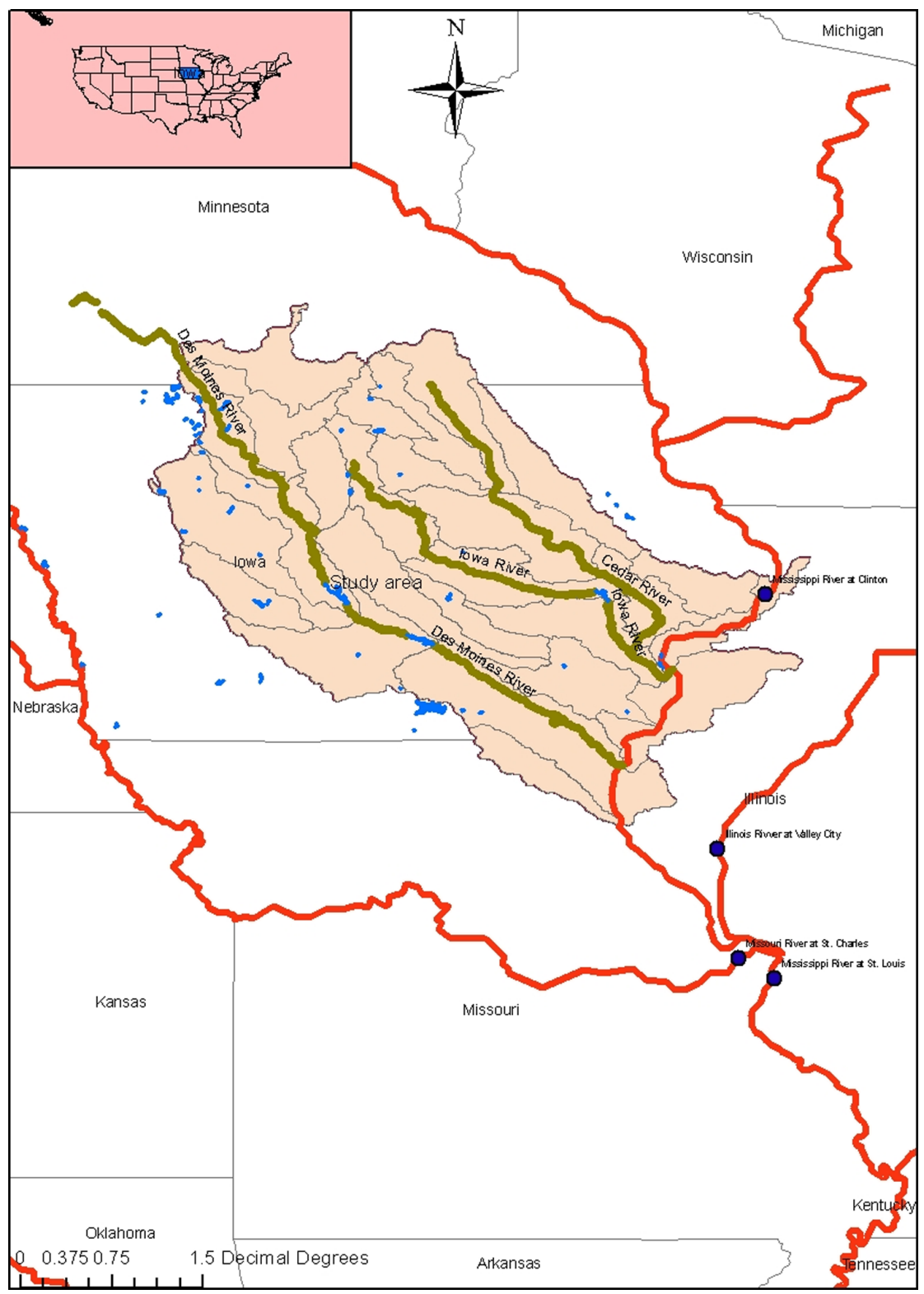

Figure 1. Study area extent (gray shaded) and location of discharge observation stations

daily from 1 March 2008 to 31 August 2008 have been collected at St Louis station (Lat. $38^{\circ} 37^{\prime} 44.4^{\prime \prime} \mathrm{N}$ and Lon. $90^{\circ} 10^{\prime} 47 \cdot 2^{\prime \prime} \mathrm{W}$ ) in the Mississippi River around 350 miles downstream, Missouri and Illinois Rivers at (Lat. $38^{\circ} 47^{\prime} 19.9^{\prime \prime} \mathrm{N}$ and Lon. $90^{\circ} 28^{\prime} 14 \cdot 6^{\prime \prime} \mathrm{W}$ ), and (Lat. $39^{\circ} 42^{\prime} 12^{\prime \prime} \mathrm{N}$ and Lon. $90^{\circ} 38^{\prime} 43^{\prime \prime} \mathrm{W}$ ), and at upstream location in the Mississippi River at Clinton station (Lat, $41^{\circ} 46^{\prime} 50^{\prime \prime} \mathrm{N}$ and Lon, $90^{\circ} 15^{\prime} 07^{\prime \prime} \mathrm{W}$ ).

\section{Polarisation ratio variation index (PRVI)}

The Robust Satellite Technique (RST) is a general change detection approach which identifies signal anomalies in the space-time domain as deviations from a normal state. The normal state is preliminarily characterized in term of expected value (e.g. time average) and corresponding variability (standard deviation). These statistical parameters are determined from satellite observations collected during several years and for each pixel, under similar observational conditions and for the same period of the year.

RST has been successfully tested in monitoring hydrometeorological processes. Lacava et al. (2005a) have developed an algorithm to monitor space-time soil wetness dynamics during major flood events (Lacava et al., 2005b, 2005c, 2006, 2007). Their analysis was expanded also to optical Advanced Very High Resolution Radiometer (AVHRR) and Moderate Resolution Imaging Spectroradiometer (MODIS) data (Faruolo et al., 2009; Lacava et al., 2009a).

In this study, we implement the RST technique using the PR and determine therefore the Polarisation Ratio Variation Index (PRVI) (Lacava et al., 2009b; Temimi et al. 2009) that is written as:

$$
P R V I_{C h}(x, y, t)=\frac{P R_{C h}(x, y, t)-\mu_{P R_{C h}}(x, y)}{\sigma_{P R_{C h}}(x, y)}
$$


where $P R_{C h}(x, y, t)$ is the PR computed for an AMSR$\mathrm{E}$ channel ' $C h$ ' (i.e. $37 \mathrm{GHz}$ in this work); $\mu_{P R_{C h}}(x, y)$ and $\sigma_{P R_{C h}}(x, y)$ are the time average and standard deviation of $P R_{C h}(x, y, t)$ computed, for the pixel centered at $(x, y)$ coordinates. The time average $\mu_{P R_{C h}}(x, y)$ and the standard deviation $\sigma_{P R_{C h}}(x, y)$ are determined from multi-annual AMSR-E imagery dataset which only contains data collected during the same month of the year and acquired at the same hour of the day. Images acquired from 2002 to 2007 were used to determine the monthly average, $\mu_{P R_{C h}}(x, y)$ and $\sigma_{P R_{C h}}(x, y)$, from March through August, on pixel-per-pixel basis. AMSRE images observed in 2008, from March through August, were used to calculate $P R V I_{C h}(x, y, t)$.

The $P R V I_{C h}(x, y, t)$ gives then, for each pixel $(x, y)$ and time $t$ of observation, the actual $P R$ excess (compared to its unperturbed conditions) weighted by its normal variability, historically assessed under similar observational conditions. Hereafter, we will use PRVI referring to $\operatorname{PRVI}_{37 G H z}(x, y, t)$. It is expected that the proposed PRVI reduces the impact of site effects (known or not) and mitigates the impact of spurious effects like those related to the presence of Radio Frequency Interference (RFI) at AMSR-E low frequencies (Lacava et al., 2009c).

If we assume that the vegetation cover has a relative slower temporal variation with respect to soil moisture and that its seasonal variation follows almost the same cycle every year, one should expect that PRVI predominately reflects changes in flooded areas and soil moisture since $\mu_{P R_{C h}}(x, y)$ and the standard deviation $\sigma_{P R_{C h}}(x, y)$ are estimated on a monthly basis to account for this seasonal variation. It is expected that PRVI increases sharply when overbank flooding occurs. PRVI should qualitatively reflect changes in total surface wetness i.e. soil moisture and open waterbodies (permanent and flooded).

Although passive microwave data are all-sky capable, atmospheric perturbations introduced by rainy clouds are inherent particularly at high frequencies such as the $37 \mathrm{GHz}$. It is therefore necessary to account for these processes. Modelling the impact of rainy clouds on the passive microwave signal is complex and not straightforward. Thus, in this study, heavy rainfall conditions were detected and masked using a threshold-based technique which utilizes observed brightness temperatures at $89 \mathrm{GHz}$ vertical polarisation. According to Grody (1991), a work on SSM/I (Special Sensor Microwave Imager) data which was expanded later by Wilheit $e t$ al. (2003) to AMSR-E observations, brightness temperatures at $89 \mathrm{GHz}$ vertical polarisation less than $210 \mathrm{~K}$ may be attributed to intense precipitation. The implementation of a more sophisticated approach is possible but it is beyond the scope of this work. Pixels corresponding to heavy rainfall conditions have been eliminated through a compositing technique which consists in retaining the latest PRVI value corresponding to non-rainy conditions over every pixel showing intense precipitation.

\section{Adjustment of the rating curve parameters}

Considering the sensitivity of PRVI to change in wetness and flooding conditions and the impact of this change on river discharge, we suggest writing the rating curve formula as:

$$
Q(t)=a \operatorname{PRVI}(t)^{b}
$$

where $\mathrm{Q}$ is the estimated discharge downstream and $a$ and $b$ are two empirical parameters. The $b$ parameter which is also known as the width exponent is an indicator of river behaviour and morphology (Smith and Pavelsky, 2008). The drainage of inundated areas and/or wet soils increases the streamflow downstream. The rating curve makes use of this causality to establish a relationship between the magnitude of the flood upstream (as sensed by PRVI) and observed discharge downstream.

The rating curve formula in Equation (2) supposes that PRVI (whether it is caused by flood or soil moisture) and discharge are in phase. However, a lag has always been observed, due to drainage delay, between the maximum of water surface area and the peak of the flow (Bindlish et al., 2009). Therefore, the rating curve formula may be written as:

$$
Q(t)=a \cdot \mathrm{PRVI}^{b}(t-d . \Delta t) \quad \text { if } t>d . \Delta t
$$

Where, $d . \Delta t$ is the delay between discharge downstream and PRVI. The time lag depends on the precipitation spatial distribution and return period. It should also depend on antecedent soil moisture conditions, surface roughness and vegetation density. So, assuming a constant time lag may lead to a disparity between estimated and observed discharge. Typically, the lag cannot exceed the time of concentration of the watershed (i.e. drainage time plus travel time). In the present study, the time lag term maximizes the value of the cross-correlation function between discharge and PRVI. The cross-correlation function is calculated at every time step and the phase lag is regularly updated.

Other factors such as the morphology of the river, its slope, and roughness can affect the relationship between the observed discharge and the remotely derived wetness through PRVI. There are also dynamic factors such as the infiltration capacity of the watershed and its runoff coefficient as well as the flood wave propagation speed. The variability of these factors has an impact on the relationship between discharge and PRVI. It is therefore necessary to monitor this impact by updating the parameters of the rating curve through the use of the Kalman filter. The application of the logarithm to Equation (3) allows writing the rating curve relationship as:

$$
\begin{aligned}
& \log (Q(t))=\log (a)+b \log (\operatorname{PRVI}(t-d . \Delta t)) \\
& \text { or } \quad \mathrm{Y}=\mathrm{B}+\mathrm{A} \mathrm{X}
\end{aligned}
$$

where: $\mathrm{Y}=\log (Q(t))$

$\mathrm{X}=\log (\operatorname{PRVI}(t-d \cdot \Delta t))$ 


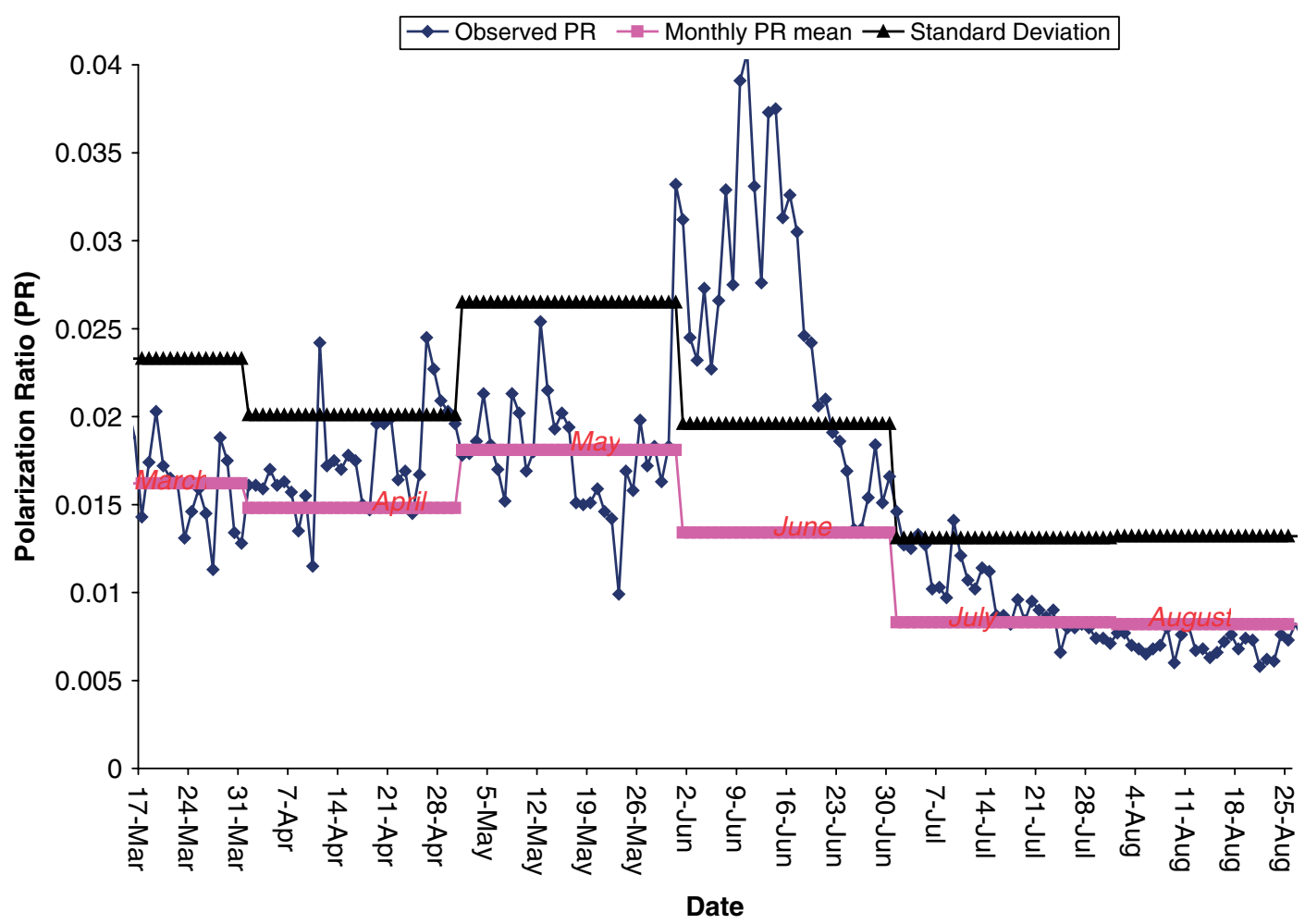

Figure 2. Seasonal variation of the areal average PR in 2008 compared to the mean and standard deviation computed for each month over the entire study area

A and B are the two model's parameters.

The Kalman filter (Johns and Mandel, 2008; Pan and Wood, 2006) is applied to the rating curve model by considering the state and the observation equations which are written as:

$$
\begin{aligned}
A_{t+1} & =\Phi_{t} A_{t}+W_{t} \\
Y_{t} & =H_{t} A_{t}+V_{t}
\end{aligned}
$$

where, $\mathrm{Y}$ subscript $=\mathrm{Y}$

$$
\begin{aligned}
A_{t} & =\left[\begin{array}{l}
A \\
B
\end{array}\right] \\
H_{t} & =\left[\begin{array}{ll}
X & 1
\end{array}\right]
\end{aligned}
$$

$\mathrm{Y}=\log (Q(t))$ and $\mathrm{X}=\log (\operatorname{PRVI}(t-d . \Delta t))$;

$W_{t}$ and $V_{t}$ are the model and observation noises which are assumed to be zero mean Gaussian white noises.

The dynamic rating curve model continuously readjusts its parameters to satisfy the non-stationary behaviour of the hydrological phenomenon. The rating curve relationship is typically site specific (Ashmore and Sauks, 2006; Frazier et al., 2003) and cannot be expanded to other rivers without a preliminary calibration step. The use of the Kalman filter adds an adaptive capability to the rating curve formula and makes it flexible and expandable to different watersheds. However, the expansion of the technique should be done with caution as it requires the existence of a minimum of causality between discharge and PRVI. A preliminary analysis is always required to verify these conditions.
It is expected that this approach leads through the development of an adaptive rating curve to a better understanding of the dynamic of the hydrological processes and the variability of key hydrologic and hydraulic parameters. It is important to note that the ultimate objective of this work is not predicting streamflow downstream but exploring the role that passive microwave can play in monitoring its variability. The adjustment of the rating curve parameters leads to an assessment of their change in time and contribute to improve our understanding of their variability with respect to watershed and rainfall characteristics. This can ultimately lead to the development of a relationship between these variables and the river's geomorphologic parameters. Such relationship may allow us to overcome the necessary calibration step in the case of standard rating curve and assess the rating curve parameters at ungauged sites (Smith and Pavelsky, 2008).

\section{RESULTS AND DISCUSSIONS}

The areal average PR tends to increase in spring until reaching a maximum in May and then decreases towards the end of the summer. Standard deviation is also the highest in May indicating significant variations of the PR which can be attributed to excessive wetness generation from snowmelt, runoff, and precipitation. The analysis of PR fluctuations covered the time period from March to August 2008. Figure 2 shows the intraseasonal variability of the observed PR which was spatially averaged over the study area. Figure 2 also compares PR to monthly 


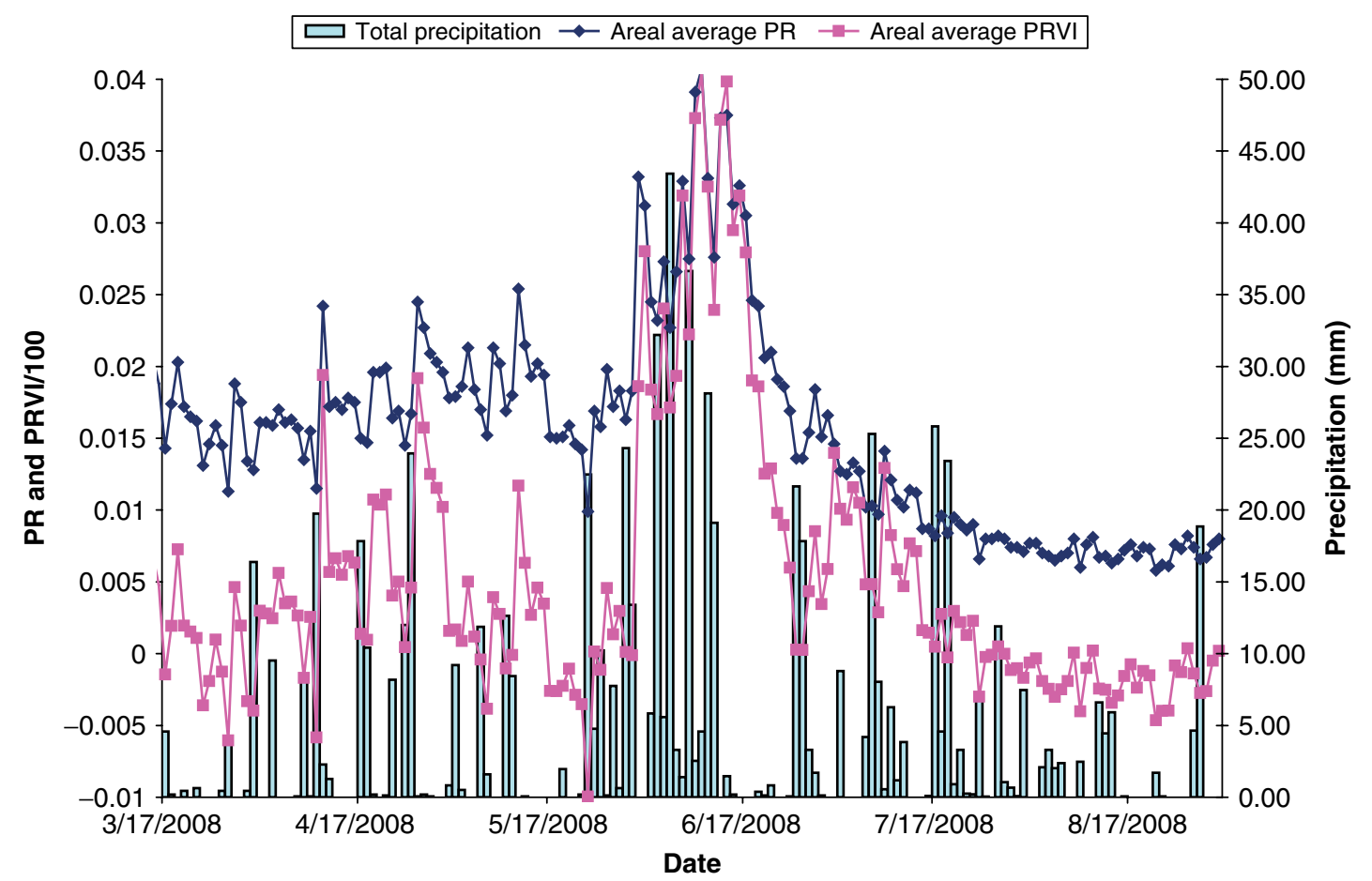

Figure 3. Calculated PR and PRVI compared to total precipitation recorded across the study area

mean and standard deviation computed through the implementation of the RST approach.

Figure 2 also shows that PR values in June 2008 were, unlike in other months, about three times above the standard deviation range. The PR reached its maximum on 10 June which corresponds to the day of the maximum flood. The exceptionally high excess of PR values in June 2008 with respect to its monthly average produced high PRVI values during the same time period. This is clearly identifiable in Figure 3, where determined PR and PRVI were compared to observed precipitation. Areal average precipitation in Figure 3 was calculated using observations made at eight stations across the state of Iowa (Table I). These observations were reported by National Climate Data center (www.ncdc.noaa.gov). The quality-controlled local climatological data product was used. The Thiessen Polygons is plotted in Figure 4 with the total rainfall observed in May, June, and July 2008 at each station. A substantial increase in observed precipitation has been noticed at all stations in June. The three stations located at Des Moines, Ames, and Mason airports recorded a significant increase in total rainfall compared to the month of May of 350, 127, and $208 \%$, respectively. This means that the central part of the state was severely affected by heavy rainfall particularly in June 2008. Most of these events were recorded in early June. This explains the substantially high areal average PR in June 2008 (Figure 2). Figure 3 shows that PRVI has also captured these events. In addition, PRVI's peak was recorded on 10 June which coincides with the flood occurrence. PR also showed a systematic increase after each rainfall event. However, Figure 3 shows that PRVI displays a higher sensitivity to rainfall (and therefore to soil moisture variations) with respect to PR. For instance, for the three rainfall events observed on 23 June, 7 July and 17 July the relative increase in PRVI with respect to increase in PR as result of the rainfall was 150,500 , and $400 \%$ higher, respectively.

The extent of the areas displaying high PRVI values was assessed and compared to USGS records of river discharges above the flood stage and to AMSR-E standard soil moisture product (Njoku et al., 2003). Figure 5a shows a PRVI map computed over the Upper Mississippi River watershed on 9 June 2008 with a clear presence of higher PRVI values in the study area as a consequence of the flood. Figure 5b presents the spatial distribution of soil moisture in the area obtained from the NASA AMSR-E product. Soil moisture was substantially high in upstream locations of the study area. Finally, Figure 5c displays the locations of water level above the flood stage in the Upper Mississippi watershed as reported by the USGS on 9 June 2008 and shows that these observations were mainly located upstream. The spatial distribution of high PRVI values is very similar to soil moisture estimates from the AMSR-E product (Figure 5 b). They also agree with the location of overbank flooding (Figure 5c). According to the spatial distribution of PRVI, extreme wetness conditions were more noticeable in upstream regions. PRVI values declined downstream towards Mississippi River. PRVI values were the highest, around eight, in the central part of the watershed. These values were higher than those obtained downstream. Figure 5b) shows few missing values in the central part of the watershed which are due to the presence of intense precipitation. The PRVI map in Figure 5a does not show a similar gap because of the implementation 
Table I. Total monthly rainfall observed at 8 stations (airports) in Iowa in 2008

\begin{tabular}{|c|c|c|c|c|c|}
\hline \multirow[t]{2}{*}{ Stations } & \multirow[t]{2}{*}{ Latitude } & \multirow[t]{2}{*}{ Longitude } & \multicolumn{3}{|c|}{ Monthly total (mm) } \\
\hline & & & May & June & July \\
\hline Des Moines international airport & 41.538 & -93.666 & 97.54 & 341.63 & $207 \cdot 77$ \\
\hline Ames municipal airport & 41.992 & -93.622 & $210 \cdot 31$ & $267 \cdot 97$ & 202.95 \\
\hline Iowa City municipal airport & 41.663 & $-91 \cdot 543$ & $125 \cdot 22$ & $205 \cdot 74$ & $9 \cdot 91$ \\
\hline Spencer municipal airport & $43 \cdot 164$ & $-95 \cdot 202$ & 91.44 & $102 \cdot 62$ & $72 \cdot 64$ \\
\hline Mason City municipal airport & $43 \cdot 158$ & $-93 \cdot 331$ & $132 \cdot 33$ & $275 \cdot 34$ & $138 \cdot 18$ \\
\hline Eppley airfield airport & $41 \cdot 31$ & -95.899 & $161 \cdot 54$ & 241.55 & $79 \cdot 50$ \\
\hline Dubuque regional airport & $42 \cdot 398$ & $-90 \cdot 704$ & $217 \cdot 68$ & $181 \cdot 86$ & $131 \cdot 06$ \\
\hline Ottumwa industrial airport & $41 \cdot 107$ & -92.448 & $125 \cdot 22$ & $250 \cdot 44$ & $59 \cdot 18$ \\
\hline
\end{tabular}

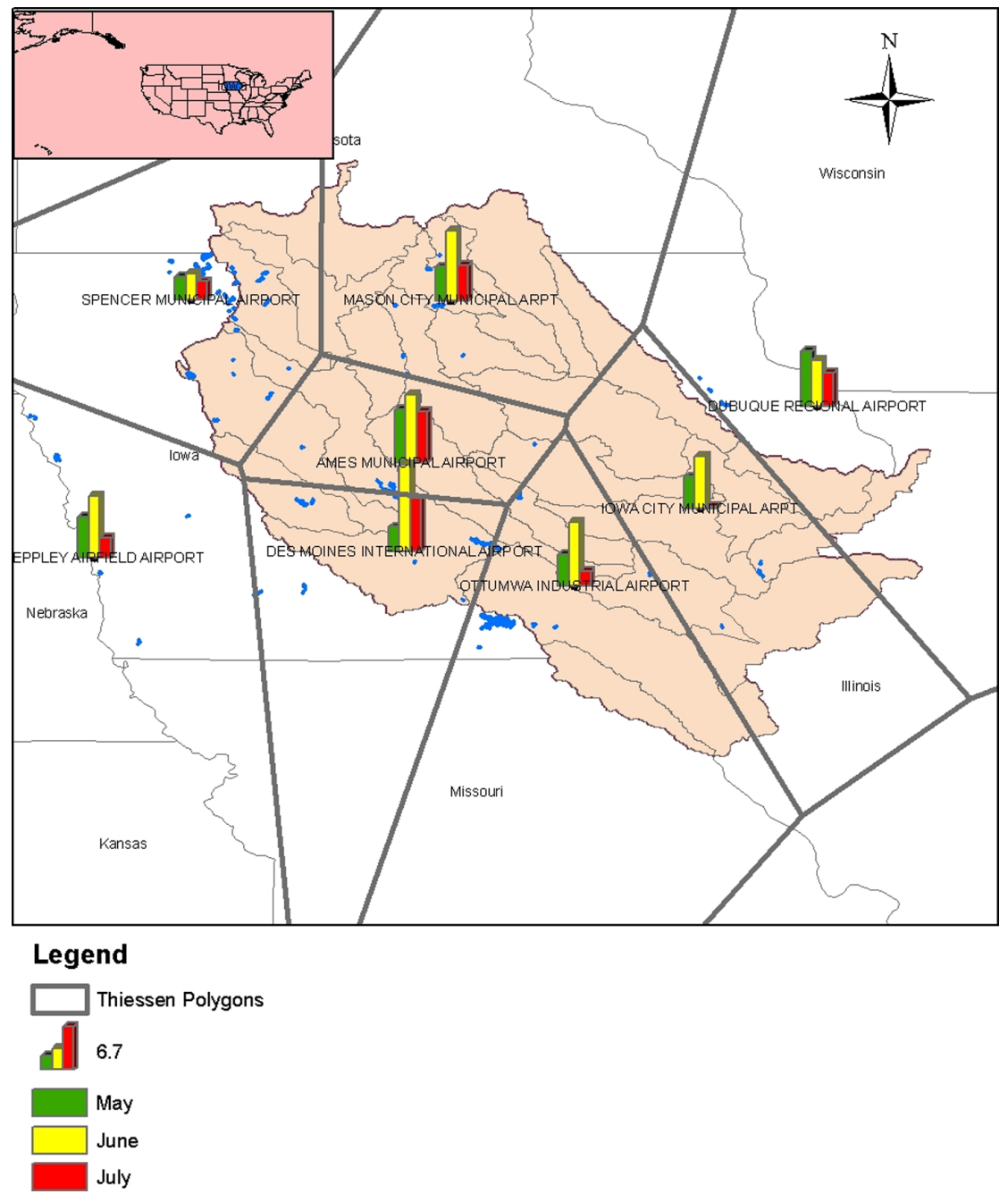

Figure 4. Observed total precipitation at eight sites in May, June, and July 2008 and their corresponding Thiessen polygons

of a compositing technique along with a threshold-based approach to systematically detect heavy rainy conditions.

The temporal variation of areal average PRVI was compared to streamflow in the Mississippi River at St Louis station (Figure 6). Missouri and Illinois Rivers' streamflow, as well as streamflow observed at Clinton station, were subtracted from St Louis station discharge observations to account only for contributions from the Iowa watershed which are referred to, hereafter, as the discharge at St Louis.
The difference in phase between the areal average PRVI and discharge downstream is illustrated in Figure 6. The peak of PRVI has been observed on 9 June. On the other hand, the streamflow peak was recorded on 2 July, 23 days later. Streamflow values have shown another increase in early May. This increase is a consequence of an earlier spring snowmelt which caused an increase in areal average PRVI in mid April. The discharge peak of $5660 \mathrm{~m}^{3} / \mathrm{s}$ recorded in early May was smaller than the observed $8700 \mathrm{~m}^{3} / \mathrm{s}$ peak during the flood event. 
(a)

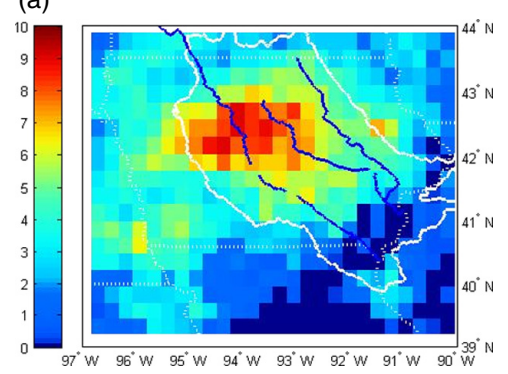

(b)

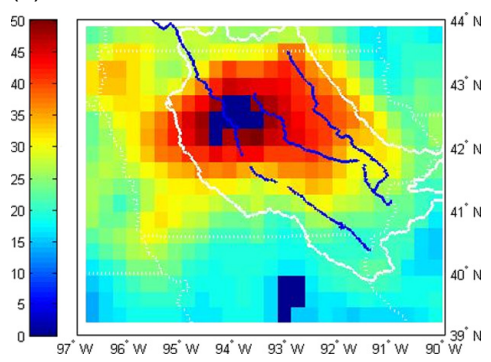

(c)

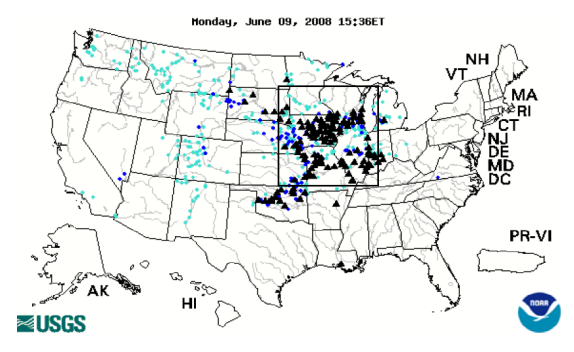

Figure 5. PRVI values obtained on 9 June 2008 in a) compared to AMSR-E soil moisture product $\left(100 \times \mathrm{g} / \mathrm{cm}^{3}\right)$ in b) and observed water levels above flood stage as provided by the USGS (black triangle) in c) (http://water.usgs.gov/osw/)

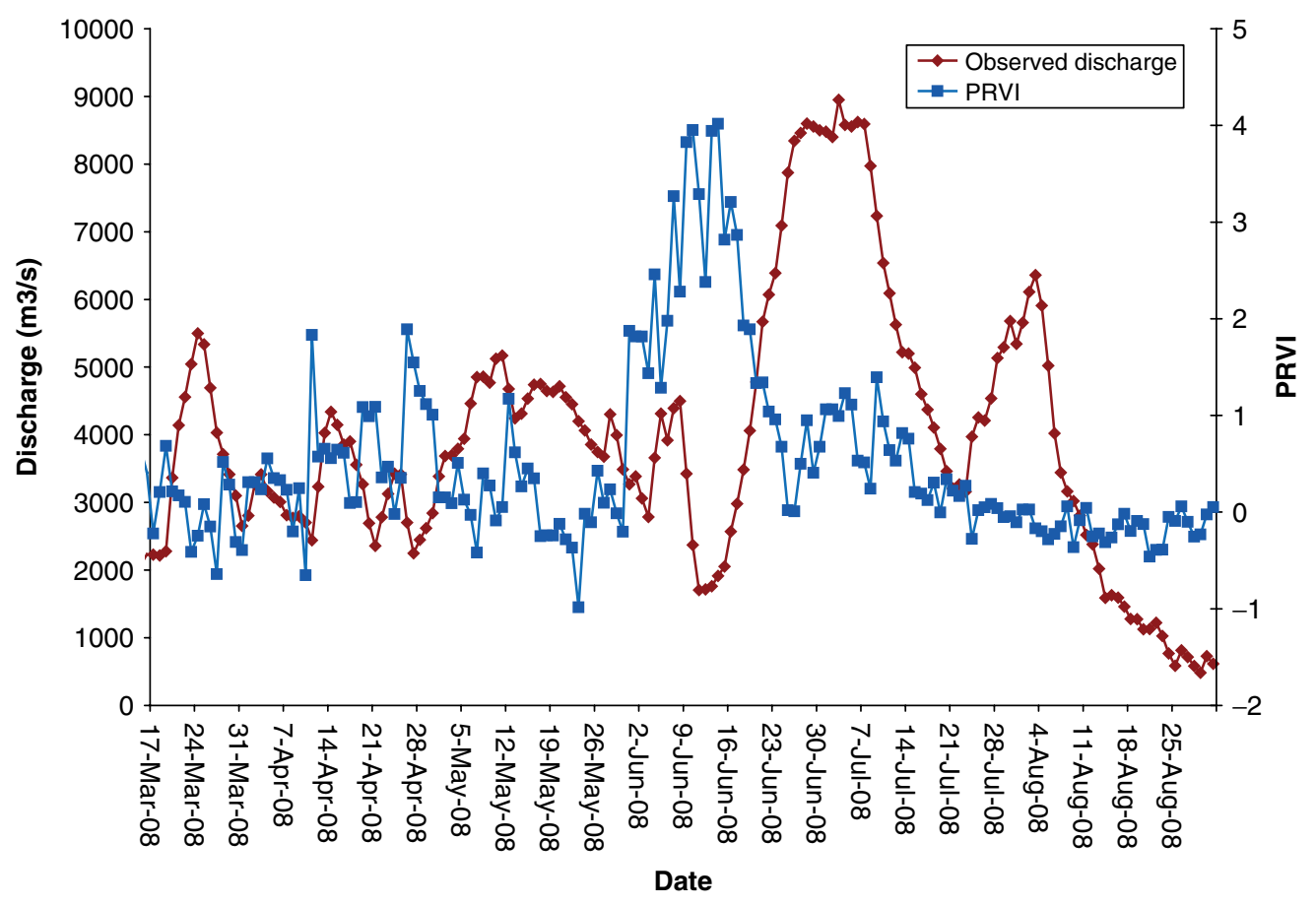

Figure 6. Observed discharge at St Louis station compared to areal average PRVI values

The increase in early May in PRVI values preceded the increase in streamflow too. However, a shorter delay of around 10 days was noticed.

According to Figure 7, a 21-day delay maximizes the correlation between PRVI and discharge downstream. The PRVI time series were smoothed using a polynomial function in order to minimize the inherent noise in the microwave signal because of the atmospheric effect. The obtained correlation when we account for the 21-day lag corresponds to $0 \cdot 8$. This delay seems to be an appropriate approximation of the time of concentration of the watershed. If we consider an average travel velocity of $1 \mathrm{~m} / \mathrm{s}$ as suggested by (Brakenridge et al., 2007; Smith and Pavelsky, 2008; Kirchner, 2009), the obtained delay of 21 days implies a travel distance of approximately $1800 \mathrm{~km}$. This distance is remarkably similar to the distance between the farthest point in the watershed and St Louis station which is approximately $1600 \mathrm{~km}$.

The lag term is adjusted at every time step with the parameters $a$ and $b$. Figure 8 compares the obtained delays to streamflow observations at St Louis Station.
In Figure 8, two sets of data can be differentiated. The first set has time lag values ranging from 2 to 11 days with a plateau at 11-day delay. These values correspond to the first flood generated by the snowmelt process in early April. On the other hand, the second set which corresponds to the flood event in June displays delays close to 21 days. It is reasonable that longer time lag is obtained with the major flood event in early June. The major flood event in June impacted a larger area and required longer drainage time. However, antecedent moisture conditions were higher in early April because of the snowmelt contribution. These higher soil moisture conditions limited the recharge, saturated the soil and, therefore, accelerated the drainage. Thus, a shorter delay was obtained in early spring. Moreover, Figure 8 shows that time lag started decreasing as soon as the discharge peak of $8700 \mathrm{~m}^{3} / \mathrm{s}$ is reached. This is due to the plateau of discharge values which lasted from 20 June to 2 July (Figure 6). This plateau indicates that the contribution of the watershed to streamflow downstream has reached its maximum which meets the definition of the time 


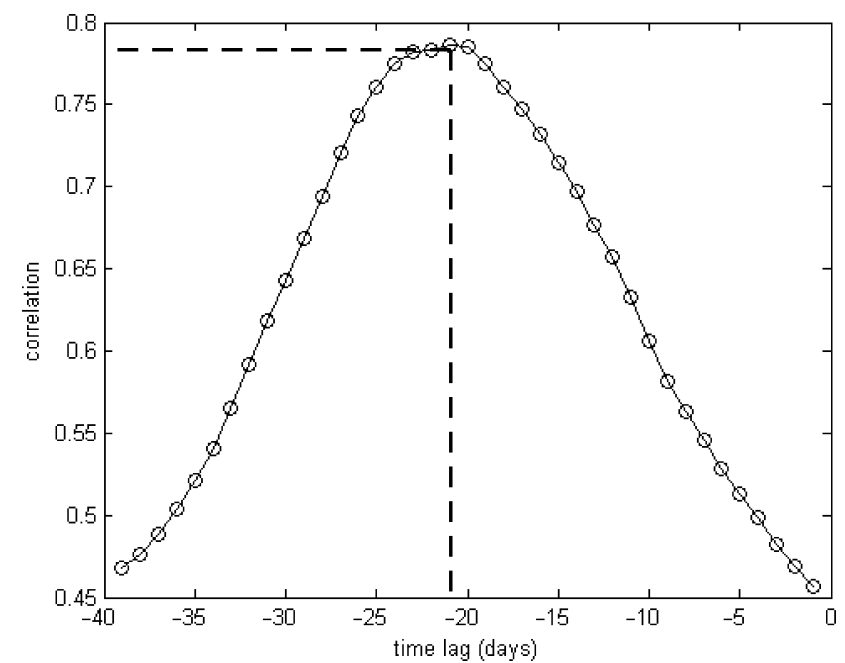

Figure 7. the 21-day time lag maximizes the correlation between PRVI and streamflow downstream observed before and after the flood event from May 15 to August $1^{\text {st }}$

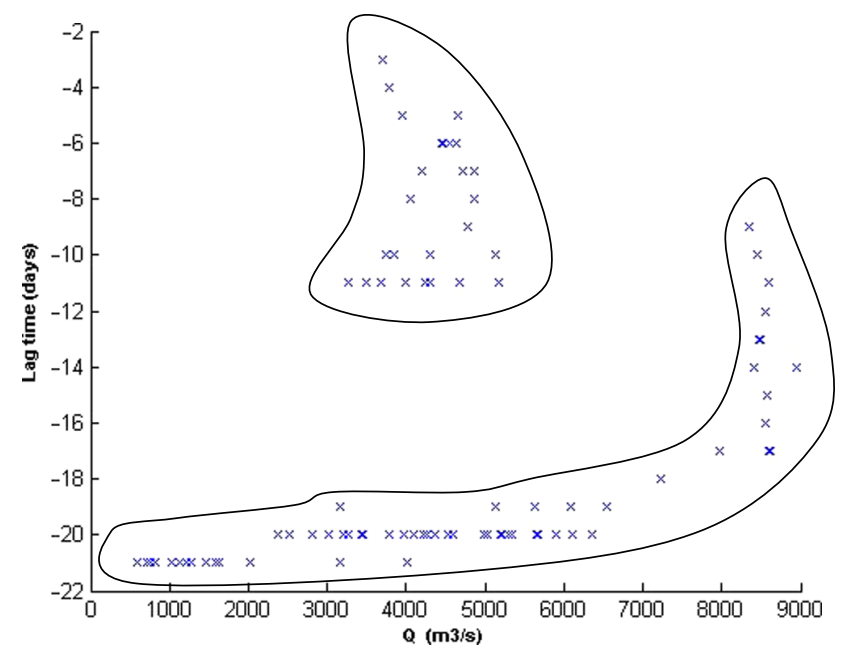

Figure 8. the variability of the determined time lags as function of observed discharge values downstream during the time period from 15 March to 30 August 2008

of concentration. The time lag has started to decline from the value of 20-day delay which corroborates the 21-day approximation determined previously for the time of concentration.

Figure 9 shows the temporal variation of the $b$ exponent in the rating curve formula. This exponent fluctuated at the early time steps of the simulation. It stabilized later and converged towards a constant value. If we exclude the fluctuation interval, the average $b$ is 0.5 and its standard deviation is 0.003 . The average $a$ parameter was 170000. The stability of the $b$ exponent towards the end of the simulation corroborates earlier findings stating that this parameter depends on the geomorphology of the drainage system. Recently, Smith and Pavelsky (2008) analysed the variability of a similar parameter in space, i.e. as a function of the reach length and have shown that the $b$ exponent converges toward a constant value. The present study has investigated its variability in time through the use of the Kalman filter and demonstrated also its convergence toward a constant value. Note that the $b$ coefficient discussed in this study is not exactly the same parameter analysed in Smith and Pavelsky (2008) as they linked the discharge to the river width as flood extent proxy.

The determined 21-day time lag and the average values of the parameters $a$ and $b$ which were obtained at the end of the adjustment process were used to estimate the discharge at St Louis station. Discharge was then estimated using constant parameters according to the standard rating curve technique. The obtained discharge is referred to hereafter as the 'estimated Q (no adjustment)'. On the other hand, the adaptive rating curve has led to the estimation of the discharge at St Louis that is referred to as the 'estimated Q (with adjustment)'. Obtained streamflow with and without adjustments were compared to the observed values at St Louis station (Figure 10). This comparison has demonstrated the significant improvement in the discharge-monitoring performances because of the continuous adjustment of the parameters $a$ and $b$ as well as the time lag. An agreement of $65 \%$ was obtained between observed discharge and estimated Q (no adjustment). The agreement was about $95 \%$ between the estimated Q (with adjustment) and the observed discharge. A better agreement, in both cases with and without adjustments, was observed during the peak of the flood in early July. During that period observed and estimated discharges were perfectly synchronous which reflects the importance of an accurate estimate of the lag term.

The combination of the rating curve and Kalman filter seems to reproduce reasonably well the discharge downstream. This study shows also that it is possible to use passive microwave data measured from space to calibrate with an acceptable accuracy the parameter of a rating curve model. Moreover, in previous studies (Frazier et al., 2003; Smith and Pavelsky, 2008), overbank flooding (effective width or surface area) has been related to discharge downstream. This study shows that beside inundated areas, soil moisture conditions which are part of the PRVI estimates have also a substantial impact on discharge downstream.

\section{CONCLUSIONS}

The PRVI, computed by implementing the RST approach using AMSR-E data acquired at $37 \mathrm{GHz}$, was applied in this work to study the flooding event occurred in Iowa during the summer of 2008. Achieved results confirm the potential of such an indicator in detecting soil wetness variations in the space-time domain, as well as flooded areas at a reasonable spatial resolution with respect to the large extent of the study area. Future works will focus on the implementation of PRVI using other AMSR$\mathrm{E}$ bands at lower frequencies, in order to exploit their higher sensitivity (at lower spatial resolution) to soil wetness conditions. Ancillary data can be used thereafter to disaggregate PRVI estimates and overcome the coarse spatial resolution of AMSR-E observations at these low frequencies (Temimi et al. 2010). 


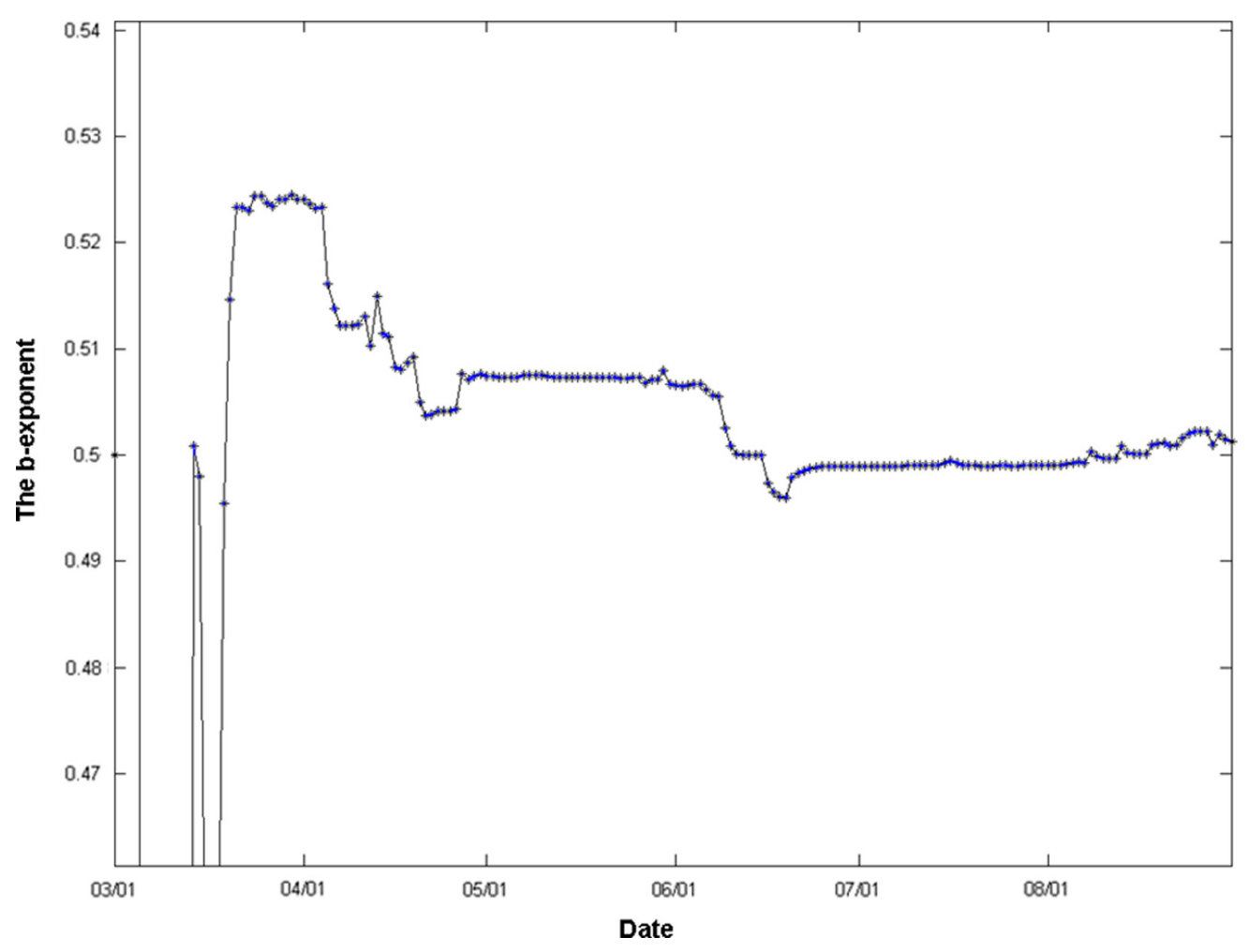

Figure 9. Temporal variation of the $b$-exponent as the result of the adjustment using the Kalman filter

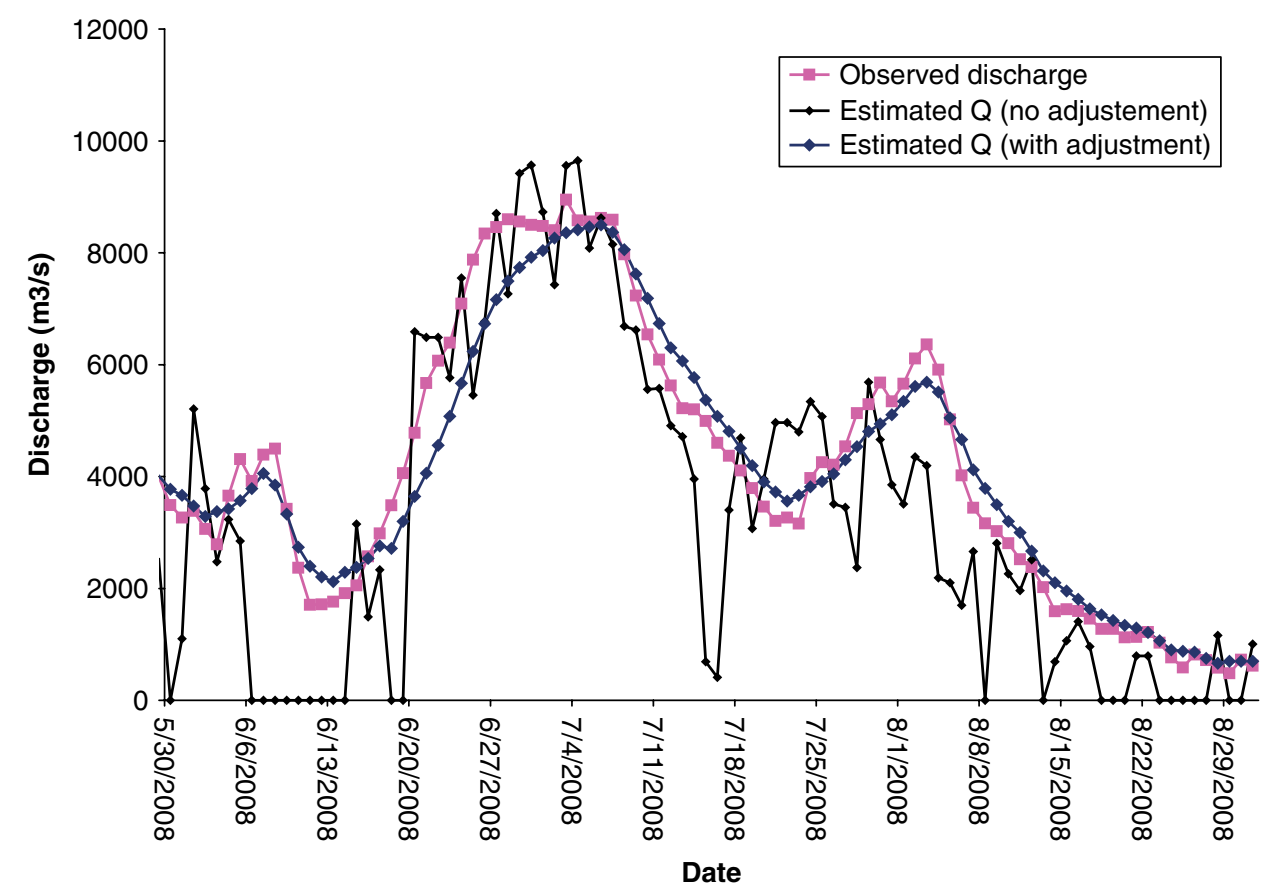

Figure 10. Comparison between estimated and observed discharge at St Louis station

Obtained results demonstrated the potential of using passive microwave data to monitor flood and discharge conditions and their capability in inferring watershed hydraulic and hydrologic parameters. This might be very useful particularly over remote ungauged watersheds. It is important to mention that measuring these parameters (such as time of concentration and flood wave propagation velocity) from space cannot substitute estimates based on in situ observations. However, satellite-based estimates of these parameters may complement and corroborate them.

The relationship between the wetness conditions upstream (soil moisture and flooding) and the discharge downstream has led to the development of a rating curve which comprises two empirical parameters. To account for the dynamic behaviour of the relationship, a Kalman 
filter was used to regularly update the parameters of the rating curve model, namely, the $a$ and $b$ coefficients and the time-lag term. The $a$ and $b$ coefficients seem to be intrinsic proprieties and, hence, site dependent. The adjustment using the Kalman filter has improved, as expected, the performance of the discharge monitoring technique. Unlike the $a$ and $b$ coefficients, the lag term seems to vary with the magnitude of the flooding to reflect the average runoff velocity and the floodwave propagation speed. So, its adjustment throughout the season is necessary. Its values, however, seem to be limited by the time of concentration of the watershed. Passive microwave data have, therefore, a great potential in estimating key hydraulic, and hydrologic parameters. These findings expand the interesting role that passive microwave data can play in monitoring flood, soil moisture, and discharge.

\section{REFERENCES}

Ashmore P, Sauks E. 2006. Prediction of discharge from water surface width in a braided river with implications for at-a-station hydraulic geometry. Water Resources Research 42(3): 11.

Bindlish R, Crow WT, Jackson TJ. 2009. Role of Passive Microwave Remote Sensing in Improving Flood Forecasts. IEEE Geoscience and Remote Sensing Letters 6(1): 112-116.

Bjerklie DM, Dingman SL, Vorosmarty CJ, Bolster CH, Congalton RG. 2003. Evaluating the potential for measuring river discharge from space. Journal of Hydrology 278(1): 17-38.

Bjerklie DM, Moller D, Smith LC, Dingman SL. 2005. Estimating discharge in rivers using remotely sensed hydraulic information. Journal of Hydrology 309(1): 191-209.

Brakenridge GR, Nghiem SV, Anderson E, Mic R. 2007. Orbital microwave measurement of river discharge and ice status. Water Resources Research 43(4): 16

Choudhury BJ. 1989. Monitoring global land surface using Nimbus-7 $37 \mathrm{GHz}$ data. Theory and examples. International Journal of Remote Sensing 10(10): 1579-1605.

Coleman JSM, Budikova D. 2010. Atmospheric aspects of the 2008 Midwest floods: a repeat of 1993? International Journal of Climatology 30(11): 1645-1667.

Crow WT, Bindlish R, Jackson TJ. 2005. The added value of spaceborne passive microwave soil moisture retrievals for forecasting rainfallrunoff partitioning. Geophysical Research Letters 32: L 18401, 5.

Faruolo M, Coviello I, Lacava T, Pergola N, Tramutoli V. 2009. Real Time Monitoring of flooded areas by a multi-temporal analysis of optical satellite data. Proceedings of 2009 IEEE International Geoscience and Remote Sensing Symposium, Vol. 4, DOI:10.1109/IGARSS.2009.5417339, pp. IV-192-IV-195.

Ferrazzoli P, Rahmoune R, Moccia F, Grings F, Salvia M, Barber M, Douna V, Karszenbaum H, Soldano A, Goniadzki D, Parmuchi G, Montenegro C, Kandus P, Borro M. 2010. The Effect of Rain and Flooding Events on AMSR-E Signatures of La Plata Basin, Argentina. Ieee Journal of Selected Topics in Applied Earth Observations and Remote Sensing 3(1): 81-90.

Frazier P, Page K, Louis J, Briggs S, Robertson AI. 2003. Relating wetland inundation to river flow using Landsat TM data. International Journal of Remote Sensing 24(19): 3755-3770.

Grody NC. 1991. Classification of snow cover and precipitation using the Special Sensor Microwave Imager. Journal of Geophysical ResearchAtmospheres 96(D4): 7423-7435.

Hamilton SK, Sippel SJ, Melack JM. 2004. Seasonal inundation patterns in two large savanna floodplains of South America: The Llanos de Moxos (Bolivia) and the Llanos del Orinoco (Venezuela and Colombia). Hydrological Processes 18(11): 2103-2116.

Hoke JE. 2009. The Midwest Flooding of June 2008: A National Weather Service Assessment, Impacts of 2008. The 89th American Meteorological Society Annual Meeting American Meteorological Society: Phoenix, AZ.

Johns CJ, Mandel J. 2008. A two-stage ensemble Kalman filter for smooth data assimilation. Environmental and Ecological Statistics 15(1): $101-110$
Kerr YH, Njoku EG. 1993. On the use of passive microwaves at $37 \mathrm{GHz}$ in remote sensing of vegetation. International Journal of Remote Sensing 14(10): 1931-1943.

Kirchner JW. 2009. Catchments as simple dynamical systems: Catchment characterization, rainfall-runoff modeling, and doing hydrology backward. Water Resources Research 45: 1-34.

Lacava T, Cuomo V, Di Leo EV, Pergola N, Romano F, Tramutoli V. 2005a. Improving soil wetness variations monitoring from passive microwave satellite data: the case of April 2000 Hungary flood. Remote Sensing of Environment 96(2): 135-148.

Lacava T, Greco M, Di Leo EV, Martino G, Pergola N, Sannazzaro F. Tramutoli V. 2005b. Monitoring Soil Wetness variations by means of satellite passive microwave observations: the Hydroptimet study cases. Natural Hazards and Earth System Sciences 5: 583-592.

Lacava T, Greco M, Di Leo EV, Martino G, Pergola N, Romano F, Sannazzaro F, Tramutoli V. 2005c. Assessing the potential of SWVI (Soil Wetness Variation Index) for hydrological risk monitoring by satellite microwave observations. Advances in Geosciences 2 $221-227$

Lacava T, Di Leo EV, Pergola N, Tramutoli V. 2006. Space-time soil wetness variations monitoring by a multi-temporal microwave satellite records analysis. Physics and Chemistry of the Earth 31: 1274-1283.

Lacava T, Di Leo, EV, Pergola N, Tramutoli V. 2007. Monitoring soil wetness variation by a multi-temporal passive microwave technique. MultiTemp 2007, DOI:10.1109/MULTITEMP.2007.4293043.

Lacava T, Pergola N, Sannazzaro F, Tramutoli V. 2009a. Improving flood monitoring by RAT (Robust AVHRR Technique) approach: the case of April 2000 Hungary flood. International Journal of Remote Sensing 31(18): 2043-2062.

Lacava T, Calice G, Coviello I, Mazzeo G, Pergola N, Tramutoli V. 2009b. Advanced Multi-Temporal Passive Microwave Data Analysis For Soil Wetness Monitoring And Flood Risk Forecast. Proceedings of 2009 IEEE International Geoscience and Remote Sensing Symposium, Vol. 3, DOI:10.1109/IGARSS.2009.5418299, pp. III-490-III-493.

Lacava T, Calice G, Coviello I, Pergola N, Tramutoli V. 2009c. A multitemporal, RST-based, AMSR-E data analysis for Radio Frequency Interference investigation: a possible impact on soil wetness retrievals In Proceedings of Multitemp 2009, Fifth International Workshop on the Analysis of Multitemporal Remote Sensing Images, 28-30 July 2009. Daniel L. Civco (ed), Mistic: Connecticut, USA; pp. 40-48.

Montanari M, Hostache R, Matgen P, Schumann G, Pfister L, Hoffmann L. 2009. Calibration and sequential updating of a coupled hydrologic-hydraulic model using remote sensing-derived water stages. Hydrology and Earth System Sciences 13(3): 367-380.

NCDC. 2008. Climate of 2008; Midwestern U.S. Flood Overview, http://www.ncdc.noaa.gov/oa/climate/research/2008/flood08.html.

Neal J, Schumann G, Bates P, Buytaert W, Matgen P, Pappenberger F. 2009. A data assimilation approach to discharge estimation from space. Hydrological Processes 23(25): 3641-3649.

Njoku EG, Chan SK. 2006. Vegetation and surface roughness effects on AMSR-E land observations. Remote Sensing of Environment 100(2): 190-199.

Njoku EG, Jackson TJ, Lakshmi V, Chan TK, Nghiem SV. 2003. Soil moisture retrieval from AMSR-E. IEEE Transactions on Geoscience and Remote Sensing 41(2): 215-229.

Owe M, De Jeu R, Walker J. 2001. A methodology for surface soil moisture and vegetation optical depth retrieval using the microwave polarization difference index. IEEE Transactions on Geoscience and Remote Sensing 39(8): 1643-1654.

Paloscia S, Macelloni G, Santi E, Koike T. 2001. A multifrequency algorithm for the retrieval of soil moisture on a large scale using microwave data from SMMR and SSM/I satellites. IEEE Transactions on Geoscience and Remote Sensing 39(8): 1655-1661.

Pan M, Wood EF. 2006. Data assimilation for estimating the terrestrial water budget using a constrained ensemble Kalman filter. Journal of Hydrometeorology, 7(3): 534-547.

RIO. 2009. Rebuild Iowa Office, Facts and Figures, http://www.rio. iowa.gov, (11 November 2009).

Schmugge T. 1998. Applications of passive microwave observations of surface soil moisture. Journal of Hydrology 213(1): 188-197.

Sippel SJ, Hamilton SK, Melack JM, Choudhury BJ. 1994. Determination of inundation area in the Amazon river floodplain using the SMMR $37 \mathrm{GHz}$ polarization difference. Remote Sensing of Environment 48(1): $70-76$

Sippel SJ, Hamilton SK, Melack JM, Novo EMM. 1998. Passive microwave observations of inundation area and the area/stage relation in the Amazon River floodplain. International Journal of Remote Sensing 19(16): 3055-3074. 
Smith LC, Isacks BL, Bloom AL. 1996. Estimation of discharge from three braided rivers using synthetic aperture radar satellite imagery: Potential application to ungaged basins. Water Resources Research 32(7): 2021-2034.

Smith LC, Pavelsky TM. 2008. Estimation of river discharge, propagation speed, and hydraulic geometry from space: Lena River, Siberia. Water Resources Research 44(3): 1-11.

Tanaka M, Sugimura T, Tanaka S. 2000. Monitoring water surface ratio in the Chinese floods of summer 1998 by DMSP-SSM/I. International Journal of Remote Sensing 21(8): 1561-1569.

Tanaka M, Sugimura T, Tanaka S, Tamai N. 2003. Flood-drought cycle of Tonle Sap and Mekong Delta area observed by DMSP-SSM/I. International Journal of Remote Sensing 24(7): 1487-1504.

Temimi M, Leconte R, Brissette F, Chaouch N. 2005. Flood monitoring over the Mackenzie River Basin using passive microwave data. Remote Sensing of Environment 98(2): 344-355.

Temimi M, Leconte R, Brissette F, Chaouch N. 2007. Flood and soil wetness monitoring over the Mackenzie River Basin using AMSRE $37 \mathrm{GHz}$ brightness temperature. Journal of Hydrology 333(2): $317-328$

Temimi M, Ghedira H, Khanbilvardi R. 2009. Flood and discharge monitoring during the 2008 Iowa flood using AMSR-E data, Geoscience and Remote Sensing Symposium, 2009. IEEE International, IGARSS 2009, pp. V-280-V-283.

Temimi M, Leconte R, Chaouch N, Sukumal P, Khanbilvardi R, Brissette F. 2010. A combination of remote sensing data and topographic attributes for the spatial and temporal monitoring of soil wetness. Journal of Hydrology 388(1): 28-40.

Tramutoli V. 2005. Robust Satellite Techniques (RST) for natural and environmental hazards monitoring and mitigation: ten years of successful applications. In The 9th International Symposium on Physical Measurements and Signatures in Remote Sensing, Shunlin Liang, Jiyuan Liu, Xiaowen Li, Ronggao Liu, Michael Schaepman (eds), ISPRS: Beijing (China); Vol. XXXVI (7/ W20), 792-795. ISSN $1682-1750$.

Tramutoli V. 2007. Robust Satellite Techniques (RST) for Natural and Environmental Hazards Monitoring and Mitigation: Theory and Applications. MultiTemp 2007, DOI:10.1109/MULTITEMP.2007.4293057.

Wilheit T, Kummerow CD, Ferraro R. 2003. Rainfall algorithms for AMSR-E. IEEE Transactions on Geoscience and Remote Sensing 41(2): 204-214. 